\title{
AVALIAÇÃO DA FERMENTAÇÃO DE CALDO DE SORGO SACARINO EMPREGANDO LEVEDURAS COMERCIAIS
}

\author{
T. F. PACHECO ${ }^{1}$, T. D. MENDES ${ }^{1}$, S. B. GONÇALVES ${ }^{1}$, R. A. C. PARRELLA ${ }^{2}$ e C. M. M. \\ MACHADO ${ }^{1}$ \\ ${ }^{1}$ Embrapa Agroenergia \\ ${ }^{2}$ Embrapa Milho e Sorgo \\ E-mail para contato: thalyta.pacheco@embrapa.br
}

\begin{abstract}
RESUMO - O sorgo sacarino tem se destacado como matéria-prima alternativa na produção de etanol, atuando de forma complementar ao cultivo da cana-de-açúcar em período de entressafra. Visando explorar o potencial deste material, empregando o caldo de sorgo sacarino BRS 511, foi avaliado o comportamento de três leveduras comerciais (CAT-1, PE-2 e SA-1) em quatro ciclos fermentativos. Utilizando a levedura CAT-1, foram conduzidas também as fermentações dos caldos das variedades BRS 506, 507, 508. Foram retiradas amostras até o completo consumo dos açúcares. Estas foram quantificadas por cromatografia líquida. Os ciclos não prejudicaram a viabilidade de nenhuma cepa. Não houve diferença no desempenho das leveduras ao longo dos ciclos. As fermentações apresentaram rendimento de aproximadamente $90 \%$ e viabilidade celular variando de 82 a $97 \%$ para todos os experimentos. Os resultados indicam que as cepas industriais estão adaptadas e os caldos aptos ao processo industrial, nas condições avaliadas.
\end{abstract}

\section{INTRODUÇÃO}

A cultura do sorgo sacarino tem se mostrado uma excelente opção na produção de bioenergia. Inicialmente, tem sido recomendada para cultivo em áreas de reformas de canaviais, visando fornecer matéria-prima para produção de etanol na entressafra da cana-de-açúcar. Apresenta as vantagens de ser uma cultura de ciclo rápido (quatro meses) e totalmente mecanizável (plantio por sementes, colheita mecânica), com alta eficiência no uso de água e nutrientes e adaptabilidade a diferentes ambientes. Entretanto, quando comparado à cana-de-açúcar, exibe menor teor de açúcar nos colmos e menor produtividade por área (May et al., 2012; Rutto et al., 2013).

Assim como a cana, o sorgo sacarino apresenta colmos dos quais se extrai o caldo contendo açúcares diretamente fermentescíveis. De maneira geral, os colmos de sorgo sacarino acumulam principalmente sacarose e alguma quantidade de glicose e frutose. O colmo é constituído, em massa, de 75 a $86 \%$ de caldo e 14 a $25 \%$ de fibras. O teor de açúcar no caldo varia de 10 a $18 \%$. A porcentagem de açúcares redutores e de sacarose no caldo depende de diversos fatores, principalmente da variedade utilizada, maturidade e tempo de colheita. (Kim et al, 2012; Durães, 2012). 


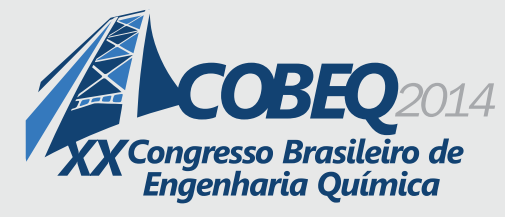

19 a 22 de outubro de 2014

Florianópolis/SC

Diante do potencial de elevação da produção de etanol pela utilização do sorgo sacarino, tornase necessário o estabelecimento dos insumos e parâmetros operacionais que permitam o aproveitamento de todo o potencial desta matéria-prima. Neste contexto, o objetivo deste trabalho foi avaliar e procurar estabelecer uma linhagem industrial de levedura com maior potencial para produção de etanol a partir do caldo de sorgo sacarino. Além disso, foram avaliados caldos de quatro variedades de sorgo sacarino produzidos pela Embrapa, visando recomendar uma mais adequada ao processo de produção de etanol.

\section{MATERIAL E MÉTODOS}

\subsection{Material}

Foram empregados, na avaliação, caldos de sorgo sacarino das variedades BRS 506, BRS 507, BRS 508 e BRS 511, desenvolvidas pela Embrapa Milho e Sorgo e selecionadas pelo potencial de acúmulo de açúcares, principalmente sacarose. Da variedade BRS 511, foram utilizadas duas amostras, com diferentes concentrações de açúcares, denominadas BRS 511 A e BRS 511 B.

Para avaliação da fermentação, foram utilizadas três linhagens de Saccharomyces cerevisiae amplamente empregadas nas indústrias: CAT-1, PE-2 e SA-1. Estas, por apresentarem boa capacidade de implantação e alta taxa de dominância, são responsáveis por uma significativa fração do etanol produzido no país em diferentes destilarias, processos, regiões e safras.

\subsection{Métodos}

Todos os caldos foram autoclavados e centrifugados. O brix (teor de sólidos solúveis) de cada um foi determinado por refratômetro manual. Para avaliação do comportamento das linhagens industriais de levedura, foram realizados quatro ciclos fermentativos empregando o caldo do sorgo sacarino BRS 511 A e o mesmo inóculo para cada uma das três cepas (CAT-1, PE-2 e SA-1). As leveduras foram cultivadas em meio rico constituído de extrato de levedura $(10 \mathrm{~g} / \mathrm{L})$, peptona bacteriológica $(20 \mathrm{~g} / \mathrm{L})$ e sacarose $(100 \mathrm{~g} / \mathrm{L})$. Após crescimento, foram retiradas do meio fermentado por centrifugação e suspensas em água estéril, formando os inóculos. A concentração celular dos inóculos foi determinada por espectrofotometria, empregando curvas padrão previamente elaboradas.

As fermentações foram realizadas em triplicata, em agitador orbital mantido a $31^{\circ} \mathrm{C}$ e $120 \mathrm{rpm}$, empregando $20 \mathrm{~g}$ de levedura por litro de caldo de sorgo, em base seca. Para evitar diluição do caldo, o inóculo foi preparado com alta concentração, de modo a representar, em média, $10 \%$ do volume total de fermentação. Foram retiradas amostras a cada 45 minutos até o completo consumo dos açúcares fermentescíveis. Após o término do primeiro ciclo, as leveduras foram centrifugadas e ressuspensas em água, formando um novo creme de leveduras de concentração conhecida. Este foi novamente inoculado em um novo caldo de sorgo sacarino, iniciando o segundo ciclo. Este procedimento foi repetido até o fim do quarto ciclo, garantindo sempre a esterilidade do meio. Ao término de cada fermentação, foi realizada a leitura do brix em refratômetro. Não houve suplementação nutricional nos caldos. 


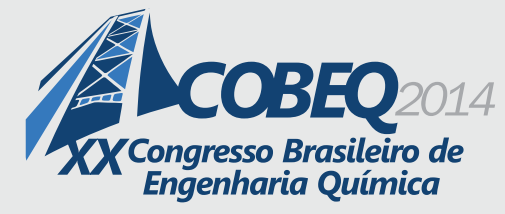

A viabilidade das leveduras no início e término de cada um dos ciclos foi determinada utilizando câmara de Neubauer e solução corante de eritrosina em tampão fosfato de sódio. O teor de sacarose, glicose, frutose, etanol e glicerol dos caldos e amostras da fermentação foram determinados por cromatografia líquida com detector RID, empregando coluna Aminex HPX-87H, com solução de ácido sulfúrico $0,005 \mathrm{M}$ como fase móvel, vazão de $0,6 \mathrm{~L} / \mathrm{min}$ e coluna a $45^{\circ} \mathrm{C}$.

Para a avaliação dos caldos de sorgo sacarino BRS 506, BRS 507, BRS 508 e BRS 511 B, foi utilizada a levedura CAT-1, com o intuito de verificar como estes diferentes materiais se comportariam frente à fermentação. As fermentações e análises foram realizadas nas mesmas condições acima mencionadas, em apenas um ciclo. As amostras foram retiradas a cada 30 minutos, em razão do menor teor de açúcares destes caldos.

\section{RESULTADOS E DISCUSSÃO}

Na Tabela 1 observam-se as concentrações de sacarose, glicose e frutose, a soma dos açúcares redutores totais (ART) e o brix de cada um dos caldos.

Tabela 1 - Concentração de açúcares e brix dos caldos de sorgo sacarino.

\begin{tabular}{cccccc}
\hline Amostra & Sacarose $(\mathrm{g} / \mathrm{L})$ & Glicose $(\mathrm{g} / \mathrm{L})$ & Frutose $(\mathrm{g} / \mathrm{L})$ & ART $(\mathrm{g} / \mathrm{L})$ & Brix \\
\hline BRS 506 & 54,25 & 11,80 & 18,64 & 87,55 & 14,20 \\
BRS 507 & 107,44 & 12,23 & 12,73 & 138,05 & 16,10 \\
BRS 508 & 62,14 & 13,09 & 25,18 & 103,68 & 15,00 \\
BRS 511 A & 143,29 & 9,25 & 9,19 & 169,27 & 17,10 \\
BRS 511 B & 57,52 & 13,76 & 20,70 & 95,01 & 12,50 \\
\hline
\end{tabular}

Pode-se observar que existe uma grande discrepância entre a concentração de açúcares dos caldos. Por razões agronômicas, as variedades BRS 506, BRS 507, BRS 508 e BRS 511 B não foram colhidas com índice de maturação adequado, portanto não exprimem o real potencial destas matériasprimas. $\mathrm{O}$ alto teor de açúcar invertido é uma das evidências de colheita precoce destas variedades.

Nas Figuras 1, 2 e 3 podem ser observados os perfis de consumo de açúcares redutores totais e formação de etanol em cada um dos ciclos para as leveduras CAT-1, PE-2 e SA-1, respectivamente. Estas concentrações consideram as médias das triplicatas, para as quais são apresentados os desvios correspondentes.

Pode-se observar que não houve diferença no tempo de consumo de ART entre os ciclos. Não houve também, para nenhuma das leveduras avaliadas, a existência de uma fase lag considerável, indicando que as leveduras não sofreram inibição na fermentação do caldo de sorgo sacarino.

As concentrações de glicerol se mantiveram baixas e semelhantes para todas as leveduras e ciclos, reforçando o fato de que as leveduras não sofreram estresse físico, químico ou microbiológico. De maneira geral, a produção de glicerol é induzida em condições de estresse osmótico motivado por altas concentrações de açúcares ou sais no mosto. 


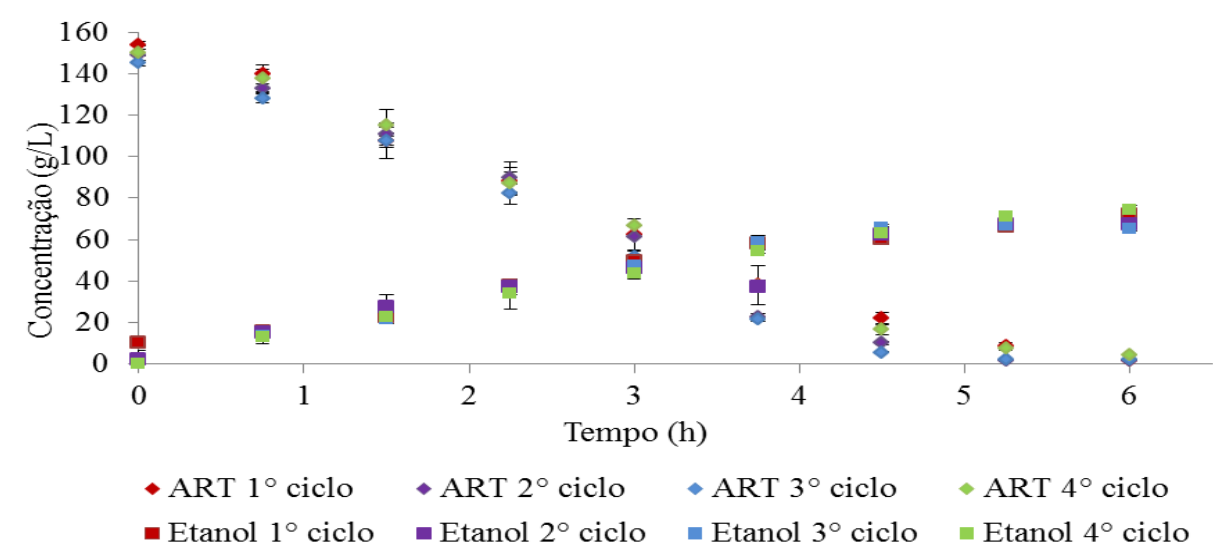

Figura 1 - Consumo de ART e produção de etanol para cada um dos ciclos utilizando CAT-1.

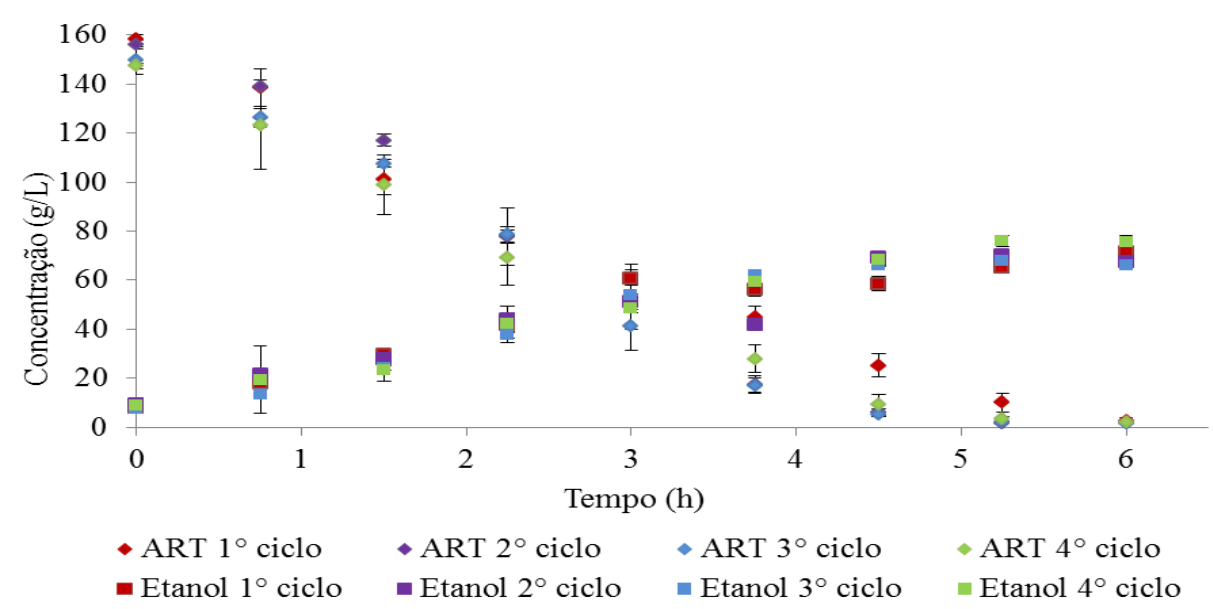

Figura 2 - Consumo de ART e produção de etanol para cada um dos ciclos utilizando PE-2.

Após o completo consumo dos açúcares fermentescíveis de cada um dos ciclos, o brix foi medido para cada ensaio e se manteve entre 5 e 5,2. Pode-se notar que, para o caldo de sorgo sacarino, a medida de brix não representa com precisão o teor de açúcares fermentescíveis, ou seja, o caldo de sorgo sacarino apresenta uma baixa pureza quando comparado ao da cana-de-açúcar.

A concentração celular, monitorada pela leitura da absorbância das amostras diluídas, mostrou que houve crescimento celular em uma taxa usual de fermentação alcoólica para caldo de cana-de-açúcar nestas mesmas condições, indicando que o caldo de sorgo sacarino não dificultou o crescimento ou provocou declínio da concentração de leveduras no meio.

Na Figura 4 são mostradas as viabilidades das cepas em cada um dos ciclos. Pode-se observar que a realização de quatro ciclos fermentativos utilizando a mesma levedura não prejudicou a viabilidade de nenhuma das cepas. Ambas as cepas aumentaram a razão de células vivas ao longo das fermentações. 


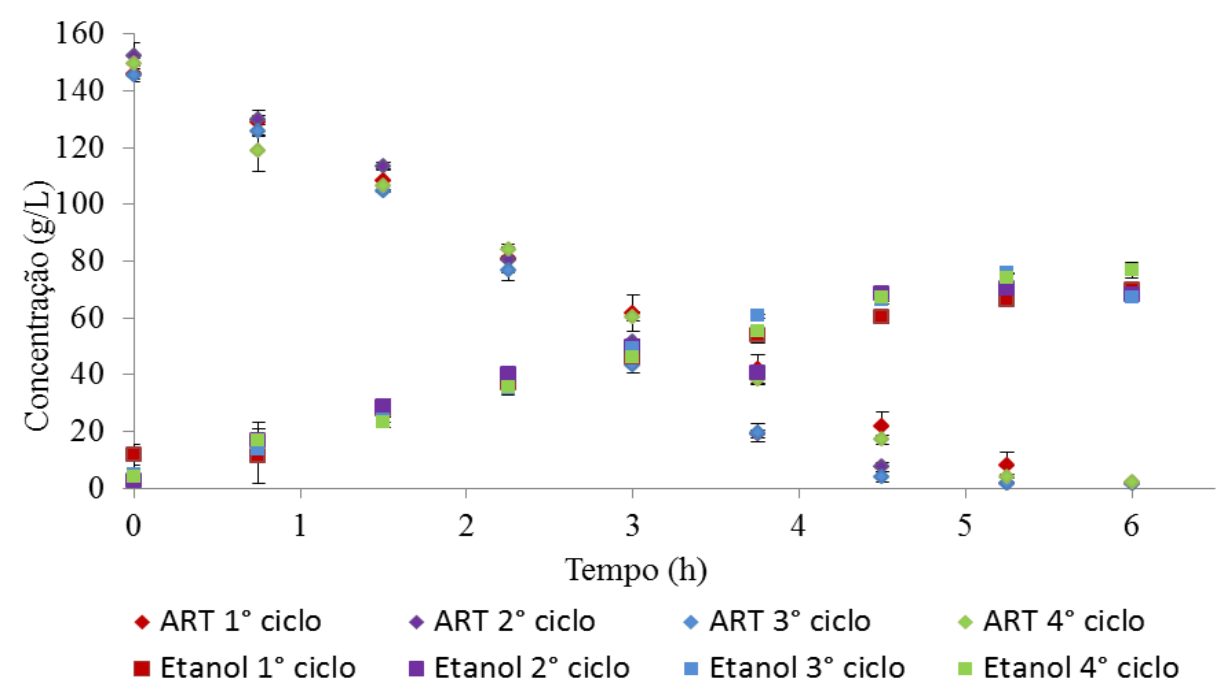

Figura 3 - Consumo de ART e produção de etanol para cada um dos ciclos utilizando SA-1.

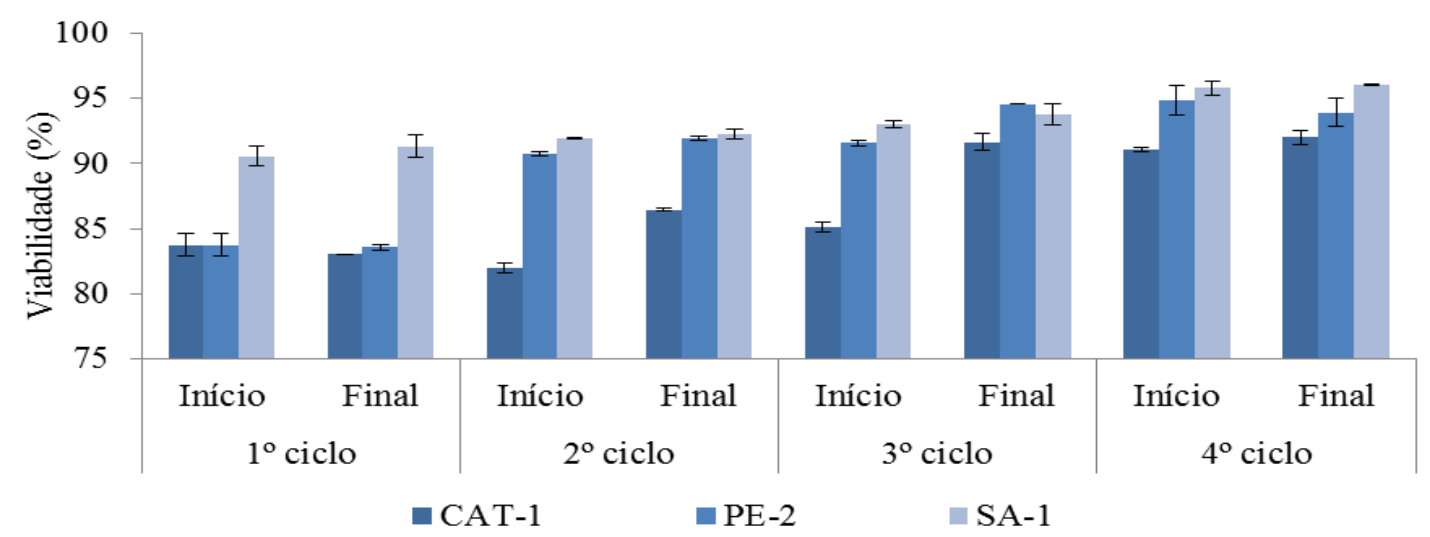

Figura 4 - Viabilidade das cepas ao longo dos ciclos.

Na Figura 5 podem ser observados os rendimentos fermentativos, em comparação com o rendimento teórico, de cada ciclo para cada uma das leveduras utilizadas. Os valores obtidos são semelhantes aos de fermentações alcoólicas feitas com meio rico ou caldo de cana-de-açúcar em escala de bancada. No quarto ciclo, pode-se observar um ligeiro aumento do rendimento em etanol, que pode ser atribuído, possivelmente, à aclimatação das leveduras ao meio. Pode-se considerar que as três leveduras apresentaram bom desempenho e podem ser consideradas adaptadas para a fermentação dos caldos de sorgo sacarino avaliados.

Mancilha et al. (1984) compararam as taxas de fermentação e os rendimentos de diferentes cepas de leveduras em caldo de sorgo. Estes obtiveram grandes variações nas 


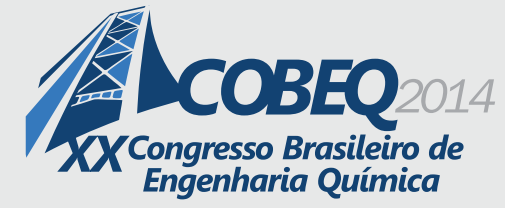

19 a 22 de outubro de 2014

Florianópolis/SC

características de fermentação trabalhando com diversas linhagens de $S$. cerevisiae. Bulawayo et al. (1996) obtiveram diferentes rendimentos de etanol (29 - 87\% do teórico) trabalhando com várias cepas de leveduras cultivadas em caldo de sorgo sacarino. Esta variação não foi observada quando as mesmas cepas foram cultivadas em meio rico. Possivelmente existiam compostos inibidores no caldo que algumas leveduras não foram capazes de tolerar.

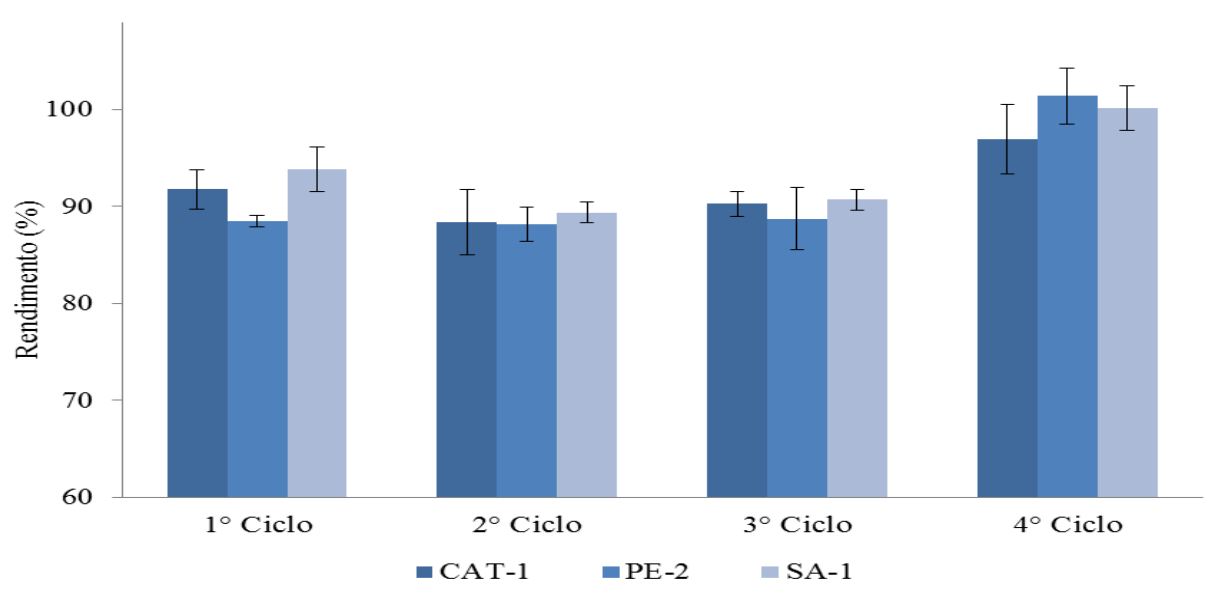

Figura 5 - Rendimentos fermentativos das cepas em cada ciclo.

Como não houve uma levedura com desempenho superior, foi então, pela disponibilidade da cepa, selecionada a levedura CAT-1 para avaliação dos caldos das variedades BRS 506, BRS 507, BRS 508 e BRS 511B. A fermentação dos caldos ocorreu em triplicata, em meio estéril, nas mesmas condições descritas para o experimento anterior. Foram inoculados $20 \mathrm{~g} / \mathrm{L}$ de levedura com viabilidade de $93 \%$.

Como as concentrações iniciais de açúcares redutores foram diferentes para cada caldo (Tabela 1), a Figura 6 mostra os perfis de consumo de glicose e produção de etanol expressas em porcentagem, possibilitando a avaliação do comportamento de cada um. Portanto, as curvas da produção de etanol já exibem o rendimento da fermentação em comparação com o teórico.

Após completo consumo dos açúcares, a viabilidade média da levedura nos quatro caldos permaneceu de $93 \%$. O brix medido para o caldo BRS 506 corresponde a 6,6, para o BRS 507 foi de 6,5; no BRS 508 de 6,8 e para o caldo BRS 511 B de 5,9.

Observou-se um maior rendimento para o caldo de sorgo da variedade BRS 506. Entretanto, como os teores de ART iniciais são diferentes, a comparação é dificultada. Como o BRS 506 apresentava menor teor de ART no caldo, o maior rendimento pode ser atribuído à menor inibição pelo substrato. Além disso, as variedades não foram colhidas em seu estágio ideal de maturação, podendo apresentar algum composto inibitório. 


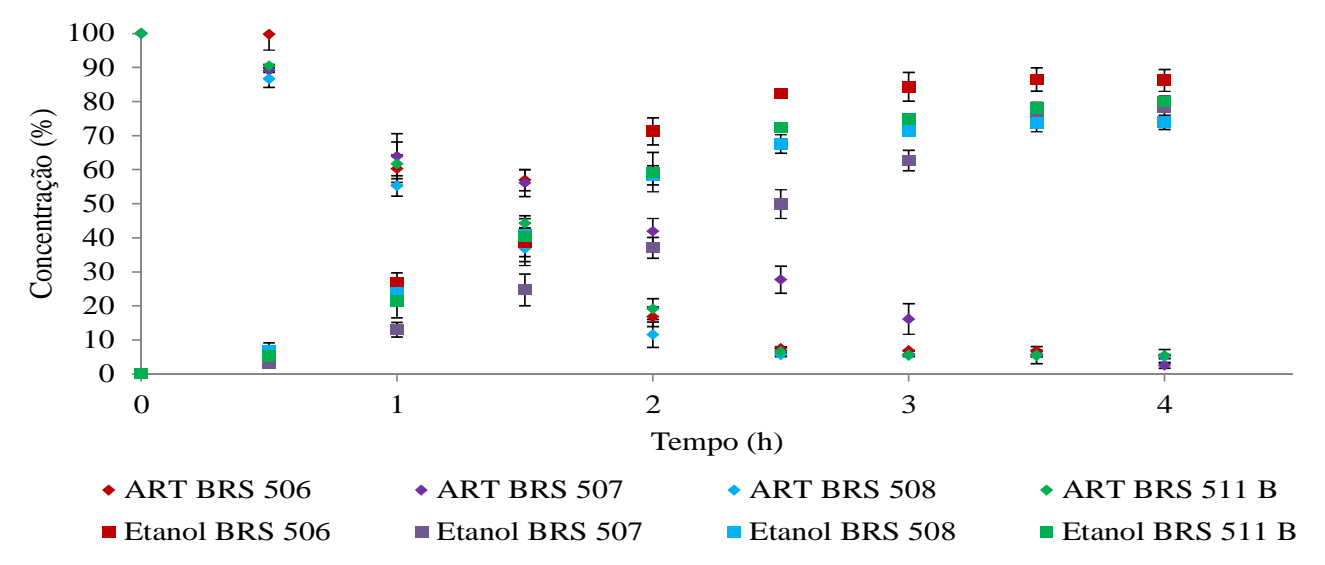

Figura 6 - Consumo de ART e produção de etanol para as quatro variedades de sorgo, utilizando a levedura CAT-1.

A comparação das fermentações dos caldos avaliados com dados apresentados na literatura é dificultada pela heterogeneidade na composição das variedades. Trupia et al. (2013) obtiveram rendimento de aproximadamente $89 \%$, empregando um caldo de sorgo com 13,7\% de açúcares redutores. Yuvraj et al. (2013), empregando caldo de sorgo sacarino suplementado com peptona, extrato de levedura e $\mathrm{MgSO}_{4}$, obteve, em 24 horas, rendimento de $79 \%$ em fermentação em erlenmeyer e de $82 \%$ em biorreator, com produtividade máxima de 3,2 getanol $/$.h. Estudos que também empregam alta concentração celular no inóculo obtiveram consumo completo dos açúcares fermentescíveis entre 4 e $14 \mathrm{~h}$. O tempo de completo consumo do ART nas fermentações se mostrou extremamente variável para os caldos avaliados (Whitfield et al., 2012; Mei et al., 2009). Assim como o presente trabalho, Laopaiboon et al. (2007), constataram a inexistência de uma fase de latência no crescimento de leveduras em sorgo sacarino, demonstrando não existirem compostos inibitórios no caldo estudado.

\section{CONCLUSÃO}

As três linhagens industriais de leveduras avaliadas se mostraram aptas para a produção de etanol a partir do sorgo sacarino, apresentando rendimentos semelhantes às fermentações com caldo de cana-de-açúcar nas mesmas condições. As quatro variedades de sorgo sacarino avaliadas, apesar de não estarem em seu índice de maturação ideal, também não ofereceram resistência ao crescimento da levedura e produção de etanol. Pode-se concluir, portanto, que, do ponto de vista da fermentação, o sorgo sacarino apresenta elevado potencial para complementação à cana-de-açúcar na produção de etanol.

\section{REFERÊNCIAS}

BULAWAYO, B.; BYOCHORA, J. M.; MUZONDO, M. I.; ZYVAUYA, R., 1996. Ethanol production by fermentation of sweet-stem sorghum juice using various yeast strains. World $J$. Microbiol. Biotechnol. 12, 357-360. 


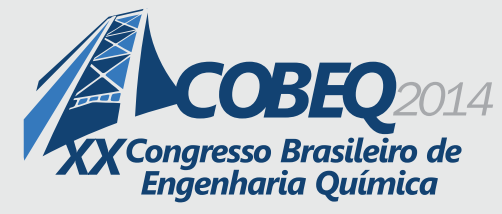

CUTZ, L.; SANCHEZ-DELGADO, S.; RUIZ-RIVAS, U.; SANTANTA, D. Bioenergy production in Central America: integration of sweet sorghum into sugar mills. Renewable and sustainable energy reviews, v. 25, p. 529 - 542, 2013.

DURÃES, F. O. O sorgo sacarino é uma alternativa para complemento da cana-de-açúcar na produção de etanol e biomassa para cogeração de energia. In: Reunião CSAA - MAPA Temática sorgo sacarino. Brasília, Agosto/2012.

KIM, M.; HAN KUN-JUN; JEONG, Y.; DAY, D. F. Utilization of Whole Sweet Sorghum Containing Juice, Leaves, and Bagasse for Bio-ethanol Production. Food Sci. Biotechnol, v. 21, n. 4, p. $1075-1080,2012$.

LAOPAIBOON, L., THANONKEO, P., JAISIL, P., LAOPAIBOON, P. Ethanol production from sweet sorghum juice in batch and fed-batch fermentations by Saccharomyces cerevisiae. World J. Microbiol. Biotechnol. v. 23, p. 1497-1501, 2007.

MANCILHA, I. M., PEARSON, A. M., WALLER, J.; HOGABOAM G. J., Increasing alcohol yield by selected yeast fermentation of sweet sorghum. I. Evaluation of yeast strains for ethanol production. Biotechnol. Bioeng. v. 26, p. 632 - 634, 1984.

MAY, A.; DURÃES, F. O. M.; PEREIRA FILHO, I. A.; SCHAFFERT, R. E.; PARRELLA, R. A. C. (Ed.). Sistema Embrapa de produção agroindustrial de sorgo sacarino para bioetanol: Sistema BRS1G-Tecnologia Qualidade Embrapa. Sete Lagoas: Embrapa Milho e Sorgo, 2012. 118 p. (Embrapa Milho e Sorgo. Documentos, 139).

MEI, X.; LIU, R., SHEN, F.; WU, H. Optimization of fermentation conditions for the production of ethanol from stalk juice of sweet sorghum by immobilized yeast using responde surfasse methodology. Energy fuels, v. 23, p. 487 - 491, 2009.

TRUPIA, S.; BAZZELL. J.; TARPINIAN, M. Sorghum Checkoff. RN002-13. Advancing Biofuels Research - NCERC at SIUE. Laboratory Research Division, 2013.

YUVRAJ; KAUR, R.; UPPAL, S. K.; SHARMA, P.; OBEROI, H. S. Chemical composition of sweet sorghum juice and its comparative potential of different fermentation processes for enhanced ethanol production. Sugar Tech, v. 15 (3), p. 305 - 310, 2013.

WHITFIELD, M. B.; CHINN, M. S.; VEAL, M. W. Processing of materials derived from sweet sorghum for biobased products. Industrial Crops and Products, v. 37, p. 362 - 375, 2012. 